Article

\title{
An Approach for Simulating Soil Loss from an Agro-Ecosystem Using Multi-Agent Simulation: A Case Study for Semi-Arid Ghana
}

\section{Biola K. Badmos ${ }^{1,2, *}$, Sampson K. Agodzo ${ }^{3}$, Grace B. Villamor ${ }^{4}$ and Samuel N. Odai ${ }^{1,2}$}

1 Civil Engineering, Kwame Nkrumah University of Science and Technology, Kumasi, Ghana; E-Mail: snodai@yahoo.com

2 West African Science Service Centre on Climate Change and Adapted Land Use (WASCAL), KNUST, Kumasi, Ghana

3 Agricultural Engineering, Kwame Nkrumah University of Science and Technology, Kumasi, Ghana; E-Mail: skagodzo7@usa.net

4 Center for Development Research, University of Bonn, 53113 Bonn, Germany; E-Mail: gracev@uni-bonn.de

* Author to whom correspondence should be addressed; E-Mail: biolakz@yahoo.com; Tel.: +234-814-212-3914; Fax: +233-3220-60137.

Academic Editors: John Wainwright and James Millington

Received: 19 December 2014 / Accepted: 19 June 2015 / Published: 24 July 2015

Abstract: Soil loss is not limited to change from forest or woodland to other land uses/covers. It may occur when there is agricultural land-use/cover modification or conversion. Soil loss may influence loss of carbon from the soil, hence implication on greenhouse gas emission. Changing land use could be considered actually or potentially successful in adapting to climate change, or may be considered maladaptation if it creates environmental degradation. In semi-arid northern Ghana, changing agricultural practices have been identified amongst other climate variability and climate change adaptation measures. Similarly, some of the policies aimed at improving farm household resilience toward climate change impact might necessitate land use change. The heterogeneity of farm household (agents) cannot be ignored when addressing land use/cover change issues, especially when livelihood is dependent on land. This paper therefore presents an approach for simulating soil loss from an agro-ecosystem using multi-agent simulation (MAS). We adapted a universal soil loss equation as a soil loss sub-model in the Vea-LUDAS model (a MAS model). Furthermore, for a 20-year simulation period, we presented the impact of agricultural land-use adaptation 
strategy (maize cultivation credit i.e., maize credit scenario) on soil loss and compared it with the baseline scenario i.e., business-as-usual. Adoption of maize as influenced by maize cultivation credit significantly influenced agricultural land-use change in the study area. Although there was no significant difference in the soil loss under the tested scenarios, the incorporation of human decision-making in a temporal manner allowed us to view patterns that cannot be seen in single step modeling. The study shows that opening up cropland on soil with a high erosion risk has implications for soil loss. Hence, effective measures should be put in place to prevent the opening up of lands that have high erosion risk.

Keywords: agricultural land-use adaptation; farm credit, climate change; Vea-LUDAS model

\section{Introduction}

Erratic rainfall is a major challenge facing agricultural practice in the semi-arid regions of West Africa. The quality as well as the amount of land and water resources accessible for agriculture and other climate-dependent sectors such as forestry and fisheries are affected by climate change [1,2]. Farmers are changing their agricultural practices and devising ways to modify livelihoods in light of the changing climate and other multiple stresses. In some cases, the changes could be considered actual or possible successes in adapting to climate change. It could also be just coping, or it may be considered maladaptation where they create environmental degradation [3]. In semi-arid northern Ghana, changing agricultural practices (e.g., crop diversification) have been identified amongst other climate variability and climate change adaptation measures [4-6]. Various policy instruments have been introduced to enhance farmers' resilience towards the impact of climate change, for example, fertilizer subsidies, farm credit, training in alternative sources of livelihood, etc. Some of these policies might require change in the agricultural land use/cover.

Soil is directly linked to many ecosystem services, hence conserving the soil will preserve and maintain the availability of these ecosystem services, such as food production, water filtration, carbon storage, etc. Soil loss is a process caused by erosion and its prepositional power [7]. The combination of climate, steep slopes, and inappropriate land use/cover patterns triggers soil erosion [8]. Various human activities, for example, population growth, removal of forest, land cultivation, overgrazing, and higher demands for firewood often cause soil erosion [9]. Soil loss may result in a decline in soil fertility and a decrease in the volume of reservoirs and water bodies due to siltation. When productivity of soil is reduced, the outputs derived from renewable natural resource systems of the biosphere are affected [10]. Soil carried by erosion also moves pesticides, soil nutrients, and other harmful chemicals into water bodies as well as ground water resources $[11,12]$. Soil erosion is also a channel through which carbon is lost from the ecosystem [13], hence the implication for greenhouse gas emissions. In Africa, decreases in productivity due to soil loss have been estimated to be between $2 \%$ and $40 \%$, with an average of $8.2 \%$ for the whole continent [14], and about $19 \%$ of the reservoir storage volumes of Africa are silted [15]. In Ghana, about $30 \%-40 \%$ of the total land area, most of which is concentrated in the northern, drier part of the country, is experiencing some form of land degradation. The soils of northern Ghana are erodible due to low organic matter content, in the range of $1.8 \%-3.2 \%[16,17]$. 
In this part of the world, soil loss due to agricultural land use change has not been adequately addressed. Agriculture is a primary source of livelihood in the semi-arid northern Ghana [18], and human decision-making will play a vital role when it comes to agricultural land use change (ALUC). We cannot ignore the heterogeneity of farm households (agents) when addressing issues on land use/cover change, especially when livelihood is primarily dependent on land. Multi-agent simulation (MAS) modeling is a data-demanding modeling approach and soil erosion/soil loss study is a resource-demanding field of study. These may have contributed to fewer applications of MAS model in the domain of soil erosion as compared to other fields. This paper therefore presents an approach for simulating soil loss from an agro-ecosystem using a multi-agent simulation (MAS) model. We simulated the impact of agricultural land use change adaptation strategy (maize cultivation credit-maize credit scenario) on soil loss and we compared the impact with the baseline scenario, i.e. business-as-usual.

\section{Methods}

\subsection{Study Area}

This study was conducted in the Vea catchment (Figure 1) in the Upper East Region (UER) of Ghana. The region is located in the northeast corner of Ghana between latitudes $10^{\circ} 30^{\prime}$ and $11^{\circ} 8^{\prime}$ North and longitudes $1^{\circ} 15^{\prime}$ West and $0^{\circ} 5^{\prime}$ East. The UER, together with the Upper West Region and Northern Region, constitute the three regions of northern Ghana. The region is bordered by Burkina Faso in the north and Togo to the east. Most parts of the region belong to the West African semi-arid Guinea Savannah [19]. The region covers a total land area of $8842 \mathrm{~km}^{2}$ and this represents about $3.7 \%$ of the total area of Ghana [20]. In the 2010 national census report [18], the UER of Ghana has a population of about $1,046,545$ habitants ( $48.4 \%$ male and $51.6 \%$ female), which constitutes about $4.2 \%$ of the total population of Ghana. The average household size in the region is 5.8 persons per household, rural locality is about $79 \%$, and about $70 \%$ of the economically active population (ages 15 years and above) are involved in agricultural activities [18].

Rainfall in the region is mono-modal and the peak of the rainy season is around July-September. The average annual rainfall is about $1044 \mathrm{~mm}$ and this is suitable for a single wet season crop [21]. About $60 \%$ of the annual rain falls between July and September. The wet period in the region is relatively short and is further marked by variations in the arrival time, duration, and intensity of rainfall [21]. The annual temperature is around $28-29{ }^{\circ} \mathrm{C}$, whereas the absolute minimum temperature is around $15-18^{\circ} \mathrm{C}[22]$.

The region has experienced a series of climate change impacts, such as a shift in seasons and irregular climatic conditions. The real problem for farmers in the northern part of Ghana is the unreliability of rainfall caused by inter-annual variability of both the total amounts and distribution of rainfall [23]. In the study area, rainfall is a key underlying factor influencing farmers' agricultural land use change options [24]. Erratic rainfall makes agricultural planning very difficult and is one of the principal sources of risk for rain-fed agriculturalists in the Sahel [23]. 


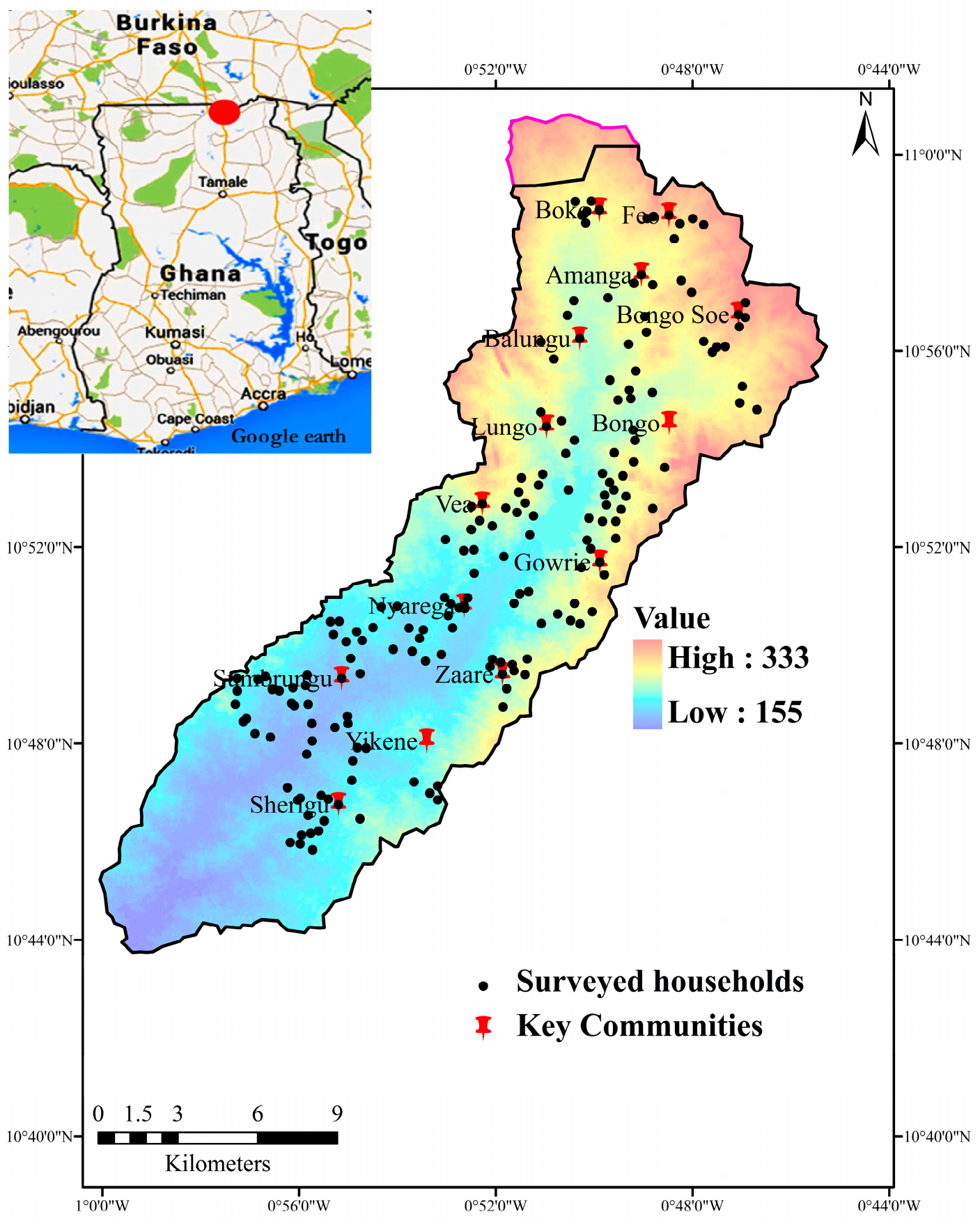

Figure 1. Elevation map of Vea catchment showing the locations of sampled farm households. The upper pink boundary represents the Burkina Faso section of the catchment.

\subsection{Household Agricultural Land Use Choice}

Seven main categories of agricultural land-use choices were identified (Table 1) from the household survey. They include traditional cereals (guinea corn culture, late millet culture, mixed-traditional culture), groundnut (monoculture groundnut, mixed-culture groundnut), rice, and maize. 
Table 1. Agricultural land-use choice classes.

\begin{tabular}{ccc}
\hline & Sub-Category/Description & Code \\
\hline 1 & Traditional cereals culture, where Guinea corn $(\mathrm{GC})$ is main crop & GC_CULT \\
2 & Traditional cereals culture, where Late millet (LM) is main crop & LM_CULT \\
3 & Traditional cereals culture, where there is an equal ratio of GC and LM & MIX_TRAD_CULT \\
4 & Groundnut in a mixture of other crops & MIX_GNUT \\
5 & Groundnut in a mono culture & MONOGNUT \\
6 & Rice is the main crop. & RICE \\
7 & Maize is the main crop. & MAIZE \\
\hline
\end{tabular}

\subsection{Model Description: Vea-LUDAS}

The Vea-LUDAS model (Figure 2) adapted the framework of Land-Use Dynamic Simulator (LUDAS) [25]. The Vea-LUDAS model is mainly based on the existing versions of LUDAS models [25-28]. The new feature of this version of the LUDAS model (i.e., Vea-LUDAS) is the incorporation of soil loss, which was parameterized in the context of the Vea catchment in the Upper East Region of Ghana.

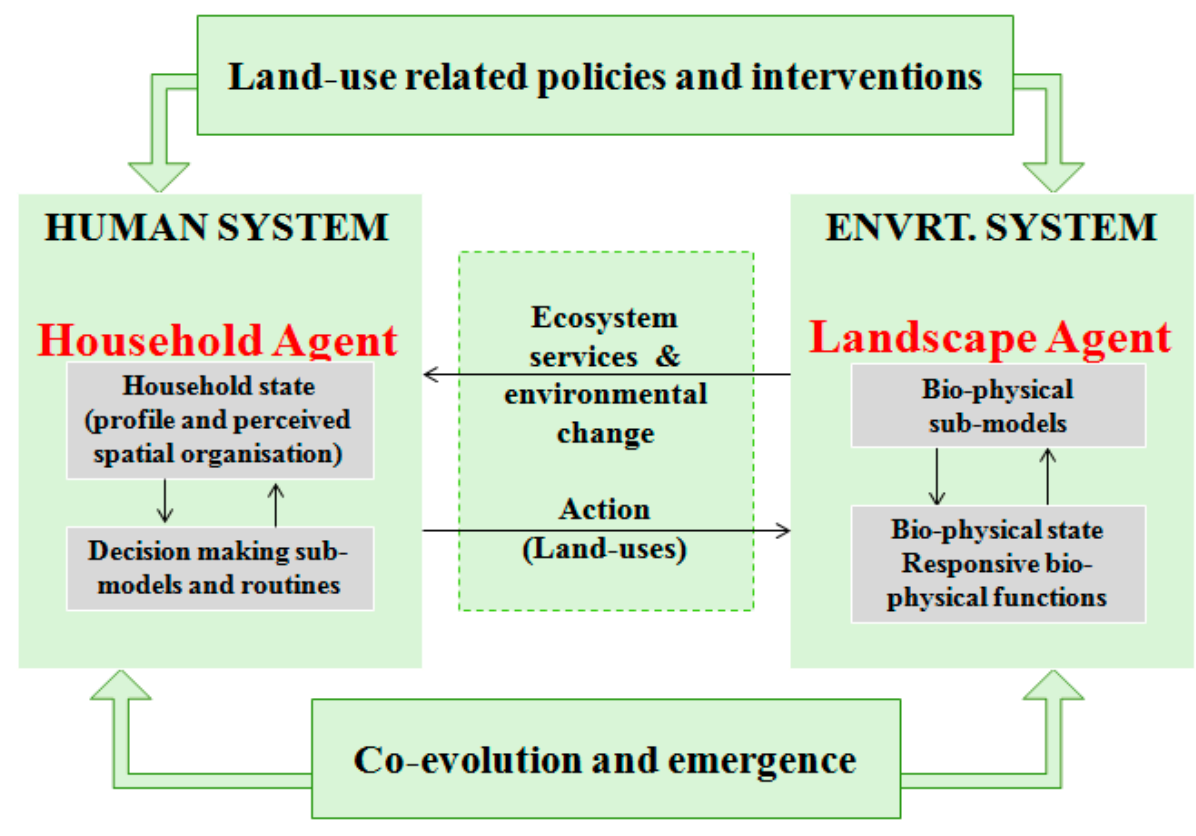

Figure 2. Vea-LUDAS framework. Adapted from [25].

LUDAS is a MAS model that was first applied to an upland watershed of about $90 \mathrm{~km}^{2}$ in central Vietnam. LUDAS was first applied by Le et al. [25] because of the heterogeneous nature of biophysical conditions, the diverse livelihood patterns of local farming households, and the need to formulate policies balancing nature conservation and economic development purposes. The description of the Vea-LUDAS model using the ODD protocol (overview, design concept, and details) [29,30] is presented in Appendix A. The ODD protocols of the Vea-LUDAS model followed similar steps to other versions of the LUDAS model. Vea-LUDAS model programming and simulation was carried out in NetLogo [31]. 
The human (household) agent and environmental (landscape) agent are the two agents in the Vea-LUDAS model and each of these agents has numerous state variables. Human agents are represented in the model as farm households (i.e., household agent) and each farm household has its spatial location, hence it can be identified with respect to its position. The state variables of human agent are household characteristics (age of household head, household size, household labor, household dependency ratio), human-plot characteristics (land holding per capita, rain-fed land holding, land area cultivated for different crops, household proximity to plots, river and irrigation area), household financial characteristics (income per capita, income from rain-fed crop). Landscape agents consist of biophysical spatial raster layers and other variables in the form of GIS-raster layers. Landscape agent is also referred to as patch and this includes biophysical features (land cover, elevation, upslope contributing area, wetness index, and soil texture components) and proximity features (plot distance to river and plot distance to irrigation area).

\subsubsection{Key Sub-Model Adapted for This Study: Soil Loss Sub-Model}

The Universal Soil Loss Equation (USLE) [32] was adapted for a soil loss estimation sub-model (Figure 3) in the Vea-LUDAS model. The USLE (Equation (1)) has been used extensively to estimate soil loss and it has also found usage in Africa. Kaolinite is the dominant clay in soils of West Africa, thus permitting the use of USLE [33]. The soil loss estimation sub-model was embedded inside the landscape module of the Vea-LUDAS model. The erosivity (R), erodibility (K), slope factor (LS), and cover factor $(\mathrm{C})$ layers were imported into Vea-LUDAS. The $\mathrm{C}$ layer is linked to land-use/cover layer. As the farm households make their cropping decisions in terms of agricultural land-use, the $C$ layer updates and soil loss is determined through the following equation:

$$
\mathrm{A}=\mathrm{R} \times \mathrm{K} \times \mathrm{LS} \times \mathrm{C} \times \mathrm{P}
$$

where $\mathrm{A}=$ Mean annual soil loss $\left(\mathrm{t} \cdot \mathrm{ha}^{-1} \cdot \mathrm{yr}^{-1}\right), \mathrm{R}=$ Rainfall/runoff erosivity $\left(\mathrm{MJ} \mathrm{mm} \cdot \mathrm{ha}^{-1} \cdot \mathrm{h}^{-1} \cdot \mathrm{yr}^{-1}\right)$, $\mathrm{K}=$ Soil Erodibility $\left(\mathrm{t} \cdot \mathrm{h} \cdot \mathrm{MJ}^{-1} \cdot \mathrm{mm}^{-1}\right), \mathrm{LS}=$ Slope length and steepness factor (Unitless), $\mathrm{C}=$ Cover and management factor (Unitless), $\mathrm{P}=$ Conservation/support practice (Unitless).

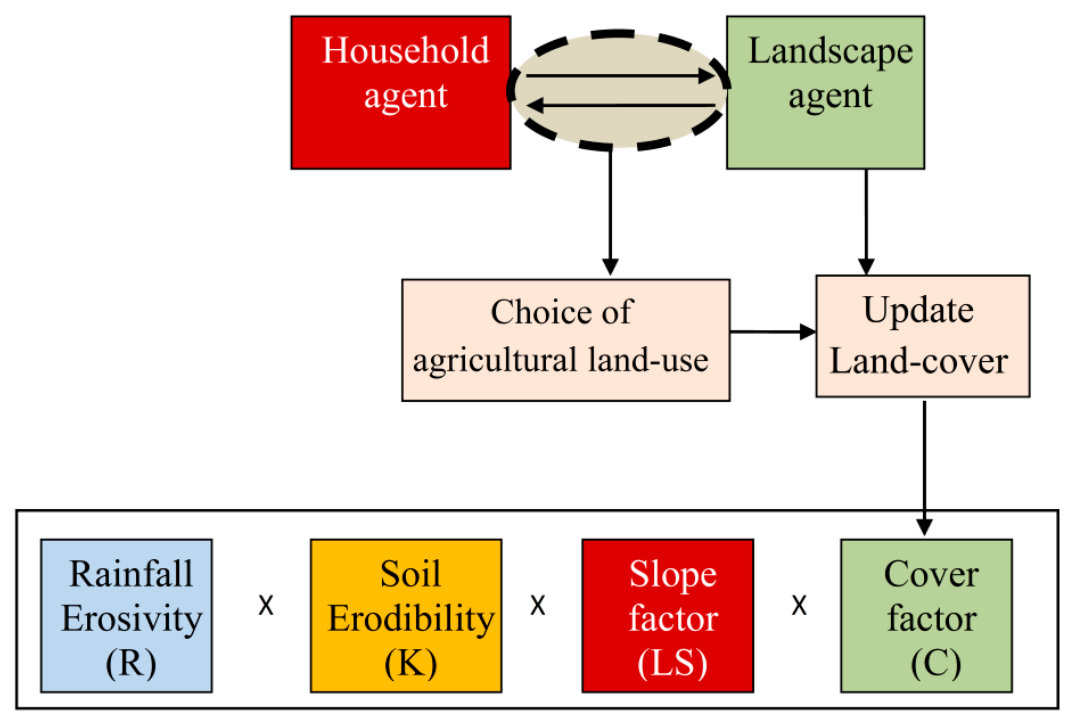

Figure 3. Soil loss sub-model. 


\subsubsection{Variable Specification for Soil Loss Estimation}

\section{Rainfall Erosivity Factor (R)}

This factor gives an indication on how erosive the rainfall is. The conventional method of estimating rainfall erosivity is the use of Erosion Index-EI 30 [32]. However, this is difficult to obtain in developing countries where continuous data availability has been a major challenge. Hence, several other methods have been developed in different parts of the world, for example, [34-38]. In some locations in West Africa, the relationship between annual rainfall and erosivity (Equation (2)) was tested and verified by [35] with 20 rainfall recording station in Cote d'Ivoire, Burkina Faso, Senegal, Niger, and Chad, excluding stations located around the mountains as well as near the sea. The Fournier index (FI) [34] has also been used to estimate rainfall erosivity, but has been improved upon with the modified version i.e., Modified Fournier index (MFI) (Equation (3)) [36]. We generated the MFI for the study area using time series rainfall data provided by the Ghana Meteorological Service Department. MFI was determined for the rainy season period of each year (April to October) and the average for the years was used. We obtained the estimated monthly Erosivity (Ri) using Equation (4).

$$
\mathrm{R}=[(0.5 \pm 0.05) \mathrm{P}]
$$

where $\mathrm{R}=$ Rainfall erosivity, $\mathrm{P}=$ Annual rainfall

$$
\text { MFI }=\sum_{i=1}^{12} P i^{2} / \mathrm{P}
$$

where $\mathrm{MFI}=$ Modified Fournier index, $\mathrm{i}=$ Months, $\mathrm{Pi}=$ average rainfall in month $\mathrm{i}(\mathrm{mm}), \mathrm{P}=$ Annual rainfall.

$$
\mathrm{Ri}=\mathrm{a}+\mathrm{b}(\mathrm{MFI})
$$

where Ri = Monthly erosivity, MFI = Modified Fournier Index, and a (21) and b (1.96) are site-specific empirical constants.

\section{Soil Erodibility (K-value)}

The K-value represents the soil loss per unit of $\mathrm{EI}_{30}$ as measured in the field on a standard plot with a length of $22 \mathrm{~m}$ and $9 \%$ slope [32]. There are three popular methods [32,39,40] used in the estimation of erodibility [41]; soil particles play an essential role in all cases. A soil erodibility nomograph was developed by Wischmeier et al. [42] to read K-value. In using the nomograph, \% silt content, \% sand content, \% organic matter, soil structural class, and soil permeability are required. In Williams et al. [39], the fine sand, silt, clay, and organic carbon content of the soil were used to estimate soil erodibility. In a data-scarce environment, an alternative method for estimating soil erodibility, i.e., ERFAC-K (Equation (5)), was proposed by Geleta [43]. In deriving the ERFAC-K, soil particles of different ratios, such as (i) silt to clay, (ii) silt to sand, and (iii) silt to sand and clay were compared with the measured K-value, and the highest coefficient of correlation (0.88) was obtained using the silt to sand and clay ratio [43]. Furthermore, soil characteristics from FAO soil database [44] were tested and a correlation coefficient of (0.82) was obtained [43]. Hence, the ERFAC-K method was adapted for the estimation of K-value as follows: 


$$
\text { ERFAC-K }=\mathrm{a}\left[\frac{\% \text { Silt }}{\% \text { Sand }+\% \text { Clay }}\right]^{\mathrm{b}}
$$

where ERFAC-K $=$ Proposed alternative soil Erodibility factor, $\%$ Silt $=\%$ silt content of the soil, $\%$ Clay $=\%$ clay content of the soil, $\%$ Sand $=\%$ sand content of the soil, $a=0.32$, and $b=0.27$.

\section{Slope Length and Steepness Factor (LS)}

Slope length and steepness are usually combined in USLE. The LS-factor represents the ratio of soil loss on a given slope length and steepness to soil loss from a $22.1 \mathrm{~m}$ slope length and a steepness of $9 \%$ under otherwise identical conditions [45]. LS factor can be calculated in various ways, for example [32,46-48]. According to Van der Knijff et al. [49], the LS equation (Equation (6)) described in Moore et al. [46,48] has the advantage over the original equation [32] because it uses specific contributing area as a slope length estimate, and this is more amenable to three-dimensional landscapes. We therefore used the method described in [49] for the estimation of the LS factor:

$$
\mathrm{LS}=\mathrm{m}+1\left[\frac{A s}{22.13}\right]^{m}\left[\frac{\operatorname{Sin} \mathrm{B}}{0.0896}\right]^{n}
$$

where $A_{s}$ is upslope contributing area, $\mathrm{B}$ is the slope in degrees, and $\mathrm{m}$ and $\mathrm{n}$ are empirical exponents.

\section{C- and P-Factor}

C-factor is the ratio of soil loss from land cropped under specific conditions to the corresponding loss from clean-tilled continuous fallow [32]. P-factor describes the erosion conservation practice put in place. The value of $\mathrm{C}$-factor depends on vegetation type, stage of growth, and cover percentage [8]. $\mathrm{C}$-factor is the most important conditional factor, and if vegetation cover is uninterrupted, erosion and runoff are small despite the erosivity of the rainfall, slope steepness, and soil instability [35]. C-factor can be estimated on the field by comparing soil loss on clean-tilled, continuous fallow with other types of land-use/cover [50]. A normalized vegetation index has also been used to estimate crop factor, for example, [51,52]. The study area is primarily agriculture based, and agriculture constitutes the main source of livelihood. Very few studies we are aware of have looked at the C-factor for different crop types in West Africa, for example [35]. In Roose [35], C-factors for different crops were presented based on the yield of crops, but the study did not provide the standard yield used in the estimation of C-factor. However, Henao and Baanante [53] summarized the C-factor for some selected cover types in Africa (Table 2). Hence we adapted C-factors presented in [53].

Table 2. Crop Cover and Management Factor for selected crops [53].

\begin{tabular}{cc}
\hline Cover Type & Cover and Management Factor $(\mathbf{C})$ \\
\hline Millet and sorghum & $0.3-0.9$ \\
Cotton & $0.5-0.7$ \\
Groundnuts & $0.4-0.8$ \\
Cowpea & $0.2-0.4$ \\
Maize & $0.4-0.7$ \\
Rice (paddy) & $0.3-0.5$ \\
Bare land & $0.8-1.0$ \\
\hline
\end{tabular}




\subsection{Scenario Exploration}

Two scenarios were tested in this study, namely (i) Baseline (BS) and (ii) maize credit scenario (MCS). BS describes the business-as-usual situation whereby the behavior of agents on the ground is that there is no policy intervention. On the other hand, MCS operates on the grounds that credit is offered to farmers for maize cultivation. The concept of MCS arose because in the northern part of Ghana, maize has been identified as an agricultural land-use adaptation practice [4,24,54]. Also, a program promoting maize cultivation was observed in the study area. For example, in the block farm program, farmers are provided with support to enable them to improve their production, and they pay back the credit in kind at the time of harvest. Maize is one of the target crops under the block farm program [55]. Hence, this study opted for maize as an agricultural land-use change option influenced by credit. The choice of household agents to accept maize cultivation followed the maize credit adoption sub-model (Figure 4). This sub-model adapted the decision-making sub-model for willingness to accept payment for ecosystem services in $[28,56]$ by following a process-based decision [56,57]. The sub-model is linked with the crop decisions of the household agent. At each time step and with respect to preferences coefficient generated using binary logistic regression, the sub-model randomly determines the probability of whether a household will accept maize credit to cultivate maize; otherwise the household uses the choice probability of his land holding. A yearly household increment of $1.2 \%$ for the study area [18] was specified in the model.

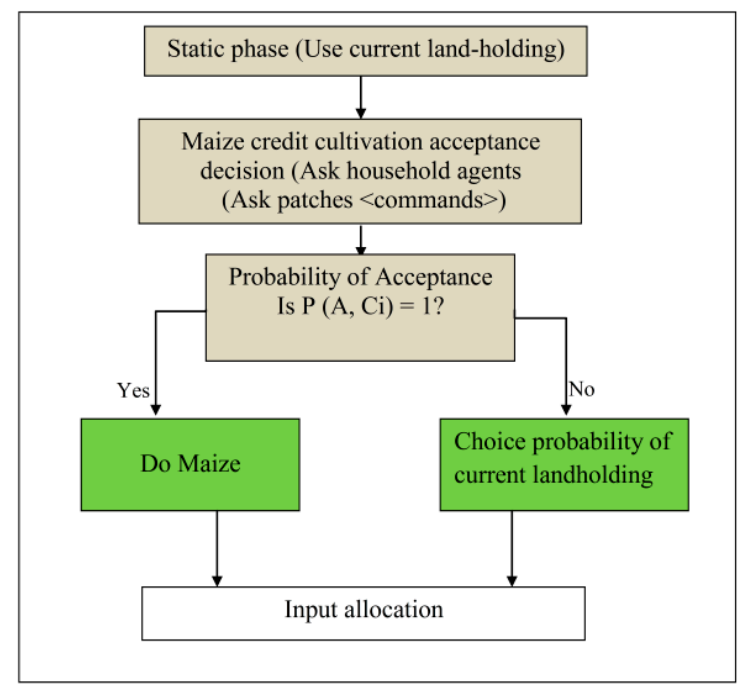

Figure 4. Maize credit adoption sub-model. Adapted from $[28,56]$.

\section{Results}

\subsection{Soil Loss Estimation Parameters}

Rainy season (April-October) rainfall erosivity between 1976 and 2012 (Figure 5) ranged between 414.9 and $701.1 \mathrm{MJ} \cdot \mathrm{mm} \cdot \mathrm{ha}^{-1} \cdot \mathrm{h}^{-1} \cdot \mathrm{yr}^{-1}$. LS-factor and soil erodibility factor are presented in (Figure 6). LS-factor ranged between from $10^{-8}$ and $3.49 \%$ (Figure $6 \mathrm{a}$ ) and the soil erodibility factor ranged from 0.026 to $0.035 \mathrm{t} \cdot \mathrm{h} \cdot \mathrm{MJ}^{-1} \cdot \mathrm{mm}^{-1}$ (Figure $6 \mathrm{~b}$ ). The highest value for soil erodibility was obtained in the fluvisol, while the least values were obtained from the lixisols. 


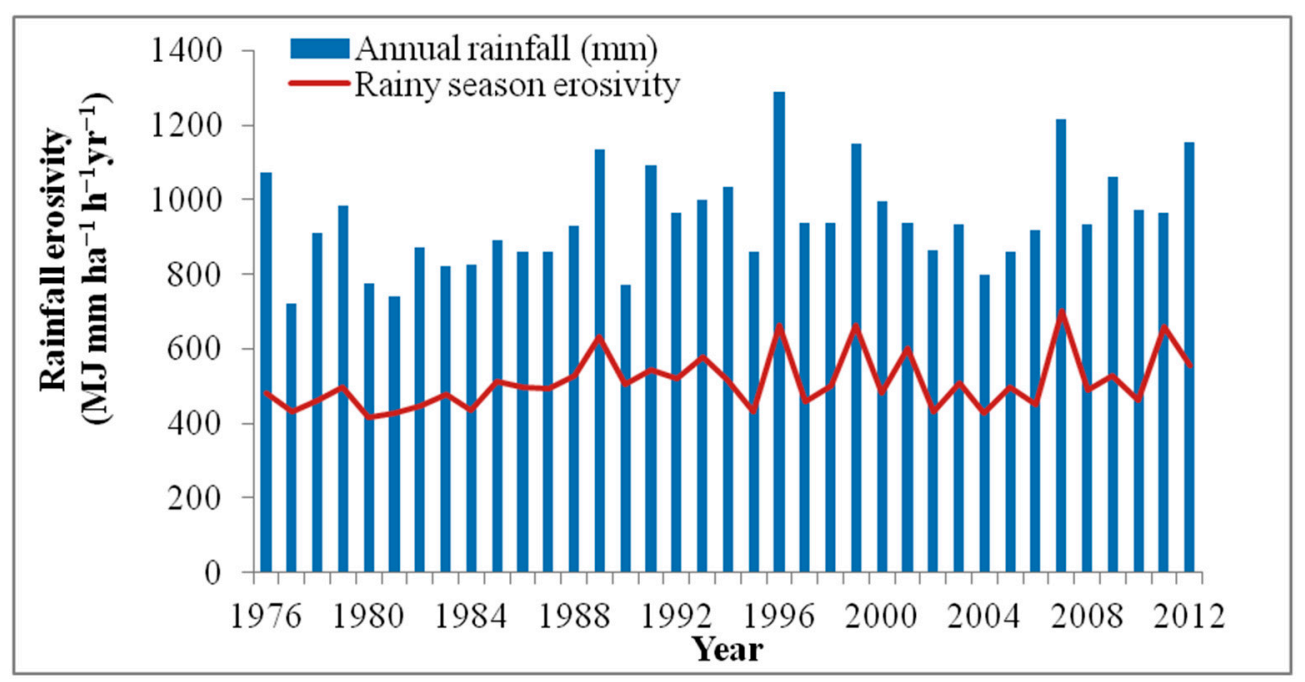

Figure 5. Rainfall erosivity.
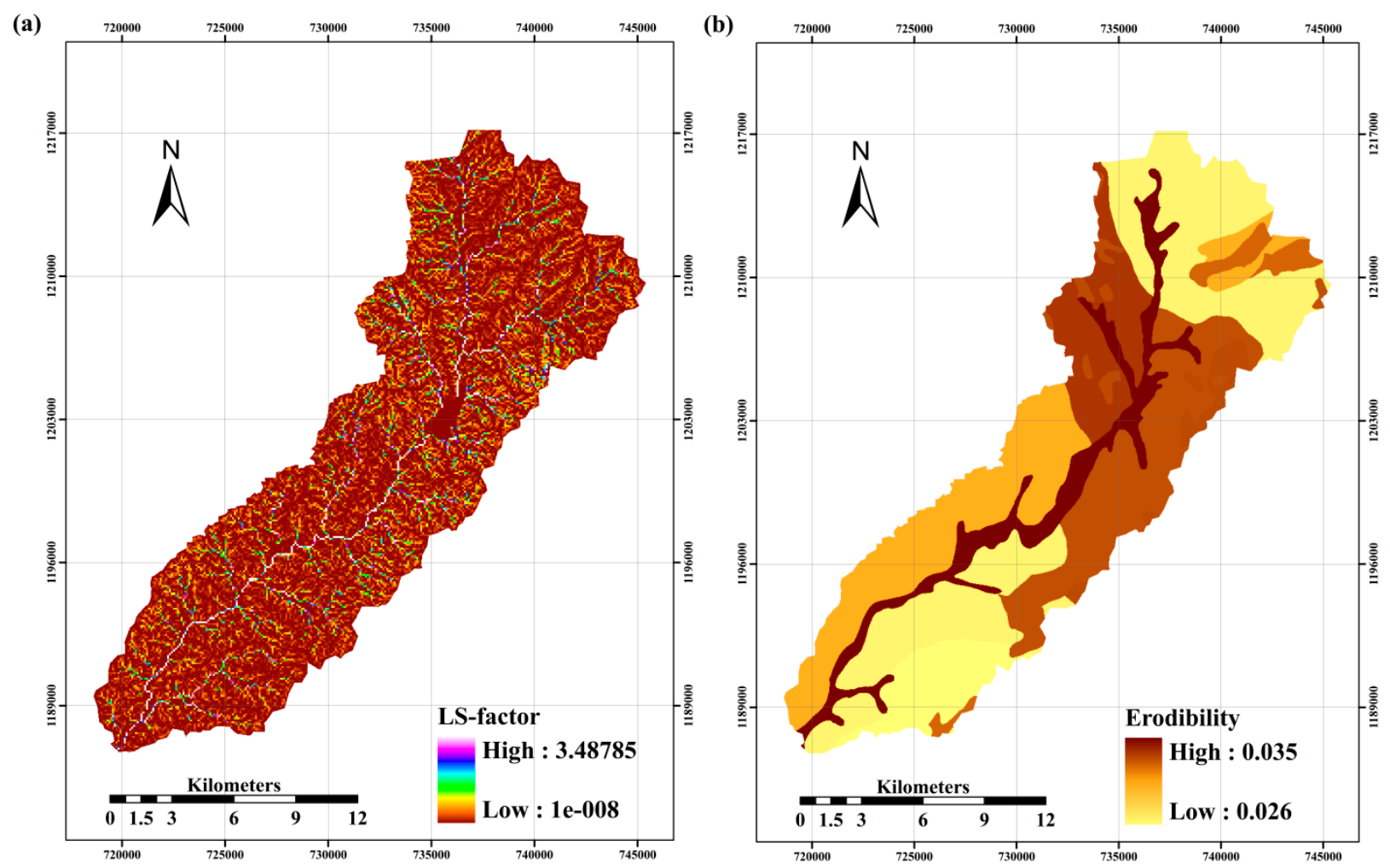

Figure 6. (a) LS-Factor $\%$; (b) soil erodibility factor- $\mathrm{t} \cdot \mathrm{h} \cdot \mathrm{MJ}^{-1} \cdot \mathrm{mm}^{-1}$.

\subsection{Agricultural Land-Use Change}

The change in area cultivated for different crops between year 1 and year 20 under the two scenarios is presented in Figure 7. Under the BS, the steady increase in the land area cultivated for different crops was attributed to the $1.2 \%$ yearly household increment specified in the model. In the case of MCS, the change in area cultivated for different crops was linked to the $1.2 \%$ yearly household increment specified in the model, as well as the influence of maize adoption rate (influenced by maize cultivation credit) at the expense of other agricultural land uses. 


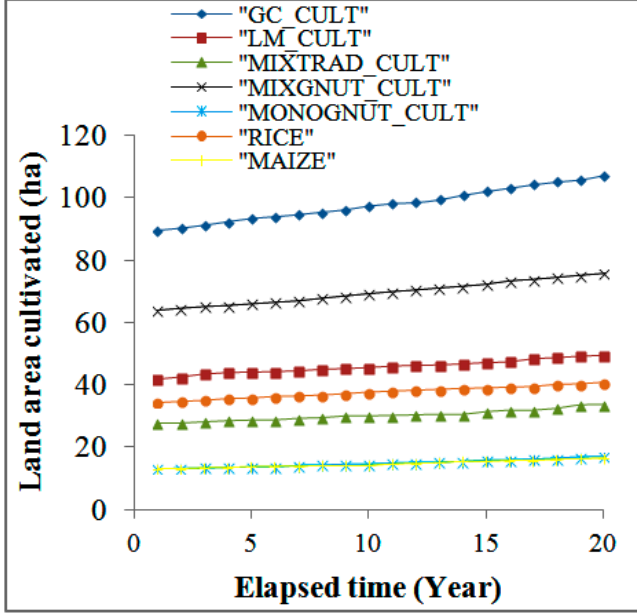

(a)

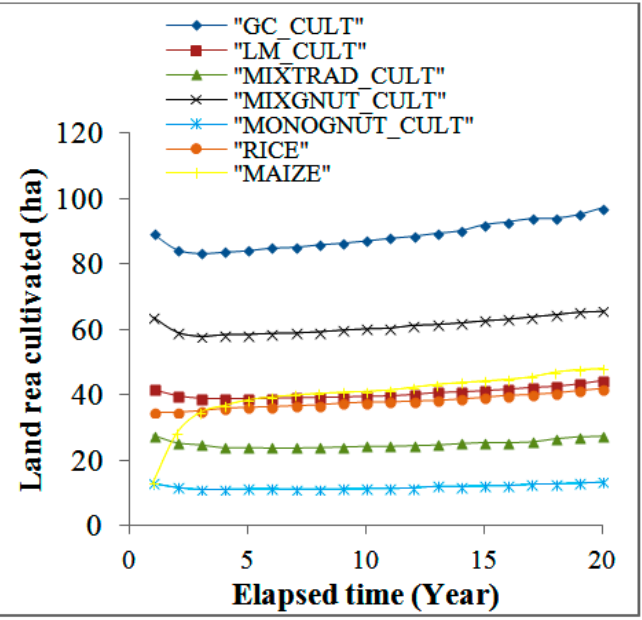

(b)

Figure 7. Simulated agricultural land-use change under the (a) BS and (b) MCS scenarios.

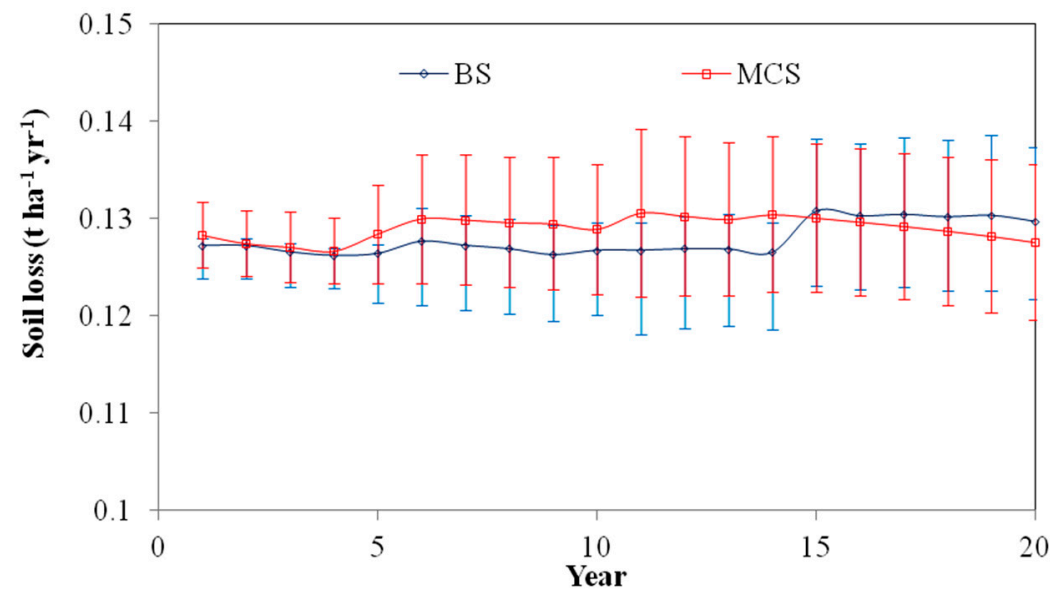

Figure 8. Simulated annual soil loss ( $p<0.05$; confidence interval 95\%).

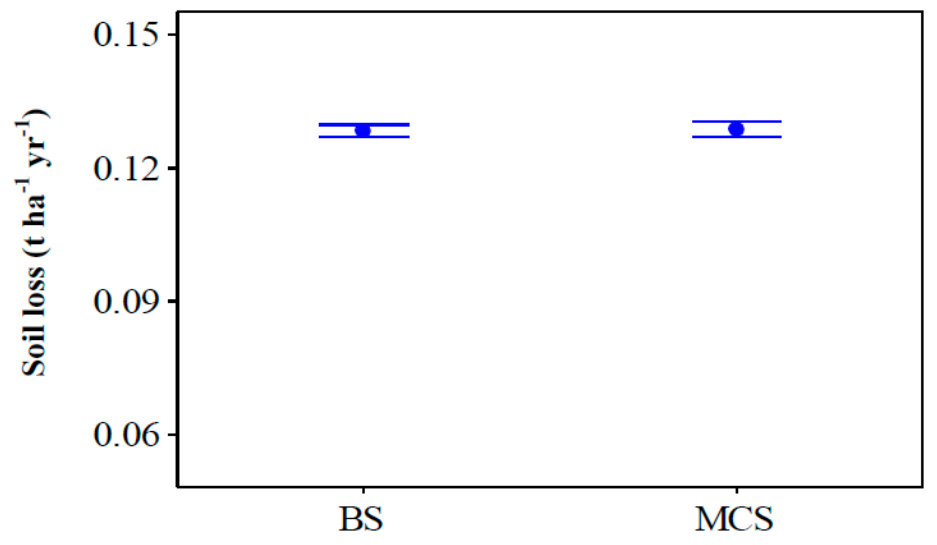

Figure 9. Average annual soil loss ( $p<0.05$; confidence interval 95\%).

\subsection{Soil Loss}

The impact of MCS on soil loss in comparison with BS showed a mixed pattern. Between year 4 and 15, simulated annual soil loss was higher under MCS as compared to BS. On the other, between year 15 and 20, 
simulated annual soil loss was higher under BS as compared to MCS (Figure 8). There was however no statistical difference $(p<0.05)$ (Figure 9) in the average simulated annual soil loss under MCS and BS.

\section{Discussion}

The application of MAS model for research has shown a tremendous increase in the last two decades [58], and this cuts across several disciplines. A key strength of the MAS model is the ability to clearly simulate the implications of human decision-making processes $[59,60]$.

In Ghana, rainfall model simulation results have showed more uncertainty compared to temperature model simulation [61]. The uncertainty in the rainfall will influence erosivity, which is the rainfall indicator for soil loss estimation. Similarly, inter-seasonal variation in rainfall will also influence rainfall erosivity and this in turn will influence the soil loss. In semi-arid Ghana, rain-fed agriculture predominates and rainfall plays a very important role in influencing agricultural land-use choice and alternatives [24]. An increase in spatial patterns of rainfall has been reported in the study area. For example, close-by locations that usually have similar rainfall patterns are now experiencing varying patterns. This situation has implications on soil loss because the cover factor will vary at different times of the year. However, this study did not consider inter-seasonal and spatial variation in rainfall and cover between different locations in the study area due to limited availability of widespread rainfall data across the study area. Furthermore, the primary farming practice in the study area is subsistence and the majority of the farmers are small holders, hence the difficulty in collecting data on the sowing and harvesting time for each type of crop cultivated. As a result of data scarcity, we settled for an alternative method of estimating the K-factor due to data limitation, which has been a huge challenge for research in Sub-Saharan Africa.

In Roose [33], C-factor is described as the most important conditional factor influencing soil loss. On the other hand, the mixed pattern observed in soil loss under the BS and MCS is associated with the fact that as farm households clear new land for crop cultivation, the type of crop cultivated on the land is not the only factor contributing to the soil loss; the influence of other biophysical characteristics (e.g., erodibility and topographic factors) of the newly cleared land also counts. This also points out the importance of incorporating farm household crop decision-making into soil loss estimation in the agro-ecosystem. It is well known that soil loss is also driven by various human activities, such as overgrazing, higher demands for fire, etc. However, this study only captured the implications of agricultural land-use change on soil loss.

\section{Conclusions}

Land-use change is second to fossil fuel burning in terms of contribution to greenhouse gas emissions. It has been reported that in the coming years, the contribution of land-use change to climate change will increase considerably. Africa will contribute significantly to the projected 9 billion people by 2050, and this implies an increase in the demand for land resources. Therefore, Africa might play a major role in future climate change. Soil erosion has an important impact on the loss of carbon from the soil into the atmosphere. We presented an approach for simulating soil loss from an agro-ecosystem using a multi-agent simulation model (the Vea-LUDAS model). Following a process-based decision approach, we simulated the impact of maize cultivation credit (maize credit scenario) on agricultural land-use 
change and subsequently the impact on soil loss. This impact was compared with the baseline scenario, i.e., business-as-usual. The Vea-LUDAS model has shown its potential to explicitly simulate soil loss from an agro-ecosystem. The temporal modeling suitability of the Vea-LUDAS model and the incorporation farm household decision-making allowed us to view patterns that cannot be seen in single step modeling. Although there was no statistical difference in the soil loss under the two tested scenarios, the simulation shows that converting high erosion risk soil to cropland has implications for soil carbon loss (i.e., climate change), which we propose to apply in areas with high erosion risk soils. Consequently, policy should be elaborated to prevent further land degradation of high erosion risk soils. Furthermore, sufficient infrastructure needs to be put in place so that reliable climatic data will be available and accessible. This is important so that farmers can have reliable information on expected weather patterns, thus enabling them to effectively plan their cultural practices and not having bare soil during the period of higher rainfall erosivity.

\section{Acknowledgments}

We thank the West African Science Service Center on Climate Change and the Adapted Land Use (WASCAL) Graduate Research Program (GRP) for providing research funds. Appreciation also goes to the field assistants and the WASCAL team. We also thank the anonymous reviewers for their valuable comments and suggestions.

\section{Author Contributions}

Biola K. Badmos was involved in the design of research, data collection and supervision of data collection, data analysis, modeling, and writing of the article. Sampson K. Agodzo contributed to the supervision of data collection and writing of the article. Grace B. Villamor contributed to the design of research, data collection and supervision of data collection process, data analysis, modeling, and writing of the article. Samuel N. Odai contributed to the supervision of data collection and writing of the article.

\section{Conflicts of Interest}

The authors declare no conflict of interest.

\section{Appendix A}

\section{ODD Protocol for Vea-LUDAS}

In this section, we describe the Vea-LUDAS using the ODD (overview, design concept, and details) protocol $[29,30]$. The Vea-LUDAS adopts/follows most of the functionalities with other LUDAS models [25-28].

\section{A1. Overview (O)}

Purpose: This study applied the Vea-LUDAS model to assess the impact of maize cultivation credits on agricultural land-use change and farm household livelihood in Vea catchment, Upper East Region of Ghana. 


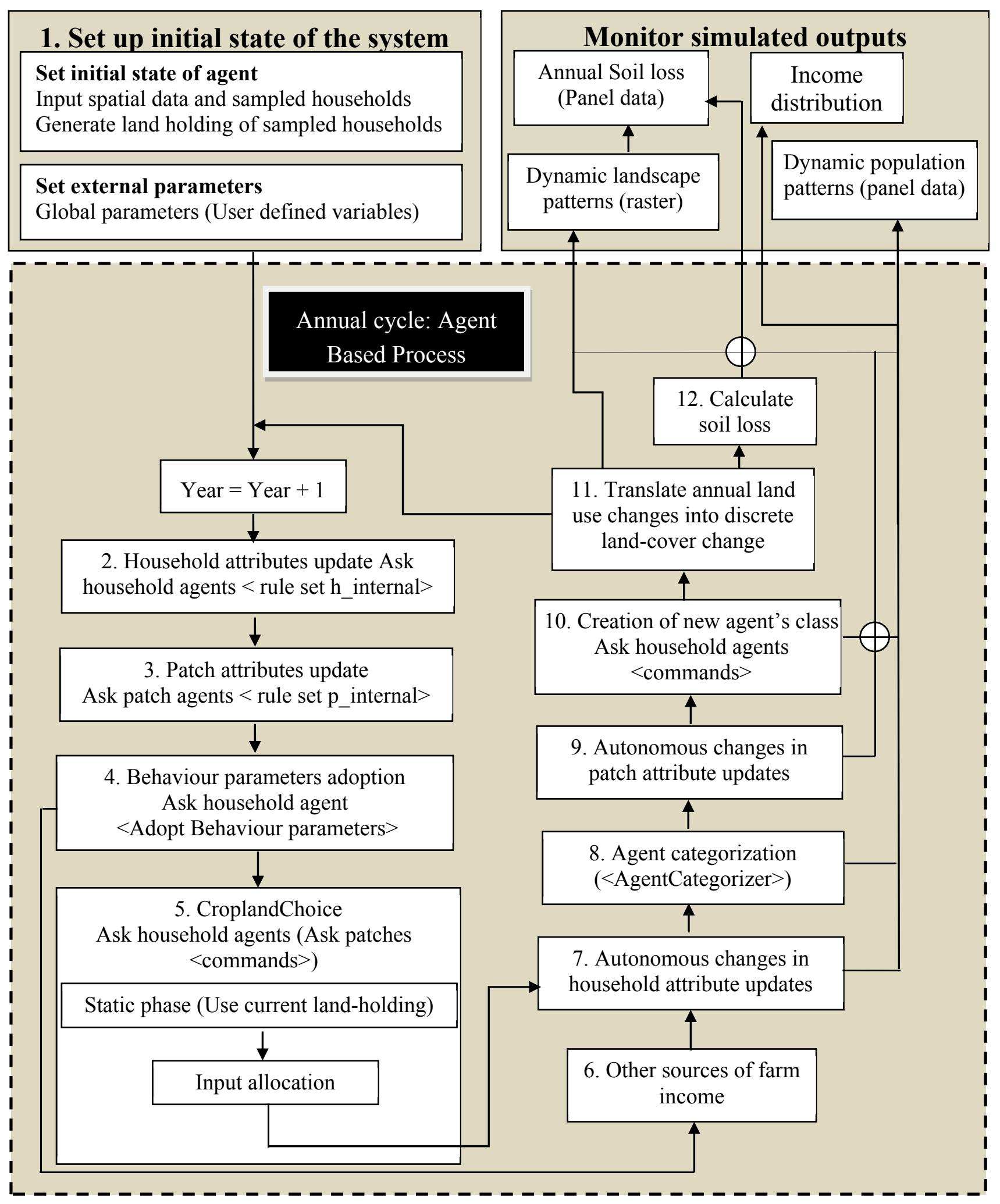

Figure A1. Main simulation steps for Vea-LUDAS (Note: Under the maize credit scenario simulation, step 5 is replaced with Maize credit adoption sub-model; dashes indicate the annual cycle of the agent-based process).

Agents and their state variables and scales: Human (household) agent and environmental (landscape) agent are the two agents in Vea-LUDAS, and each agent has numerous state variables. The human agent (i.e., household agent) is represented in the model as farm household. Each household has its spatial 
location and can be identified with respect to its position. The state variables of human agent are household characteristics (e.g., age of household head, household size, household labor, household dependency ratio), human-plot characteristics (e.g., land holding per capita, rain-fed land holding, land area cultivated for different crops, household proximity to plots, and river and irrigation area), and household financial characteristics (e.g., income per capita, income from rain-fed crop). The landscape agent comprises the biophysical spatial raster layers and other variables in the form of GIS-raster layers. Landscape agent is also referred to as patch, and this includes biophysical features (e.g., land cover, elevation, upslope contributing area, wetness index, and soil texture components), and proximity layers (e.g., plot distance to river and plot distance to irrigation area).

Vea-LUDAS captures the whole Vea catchment $\left(286 \mathrm{~km}^{2}\right)$ in the upper east region of Ghana, and is represented by grid or pixel layers $\left(30 \mathrm{~m} \times 30 \mathrm{~m}=900 \mathrm{~m}^{2}\right)$. A $900-\mathrm{m}^{2}$ grid was used because of the form in which other spatial data were available and to avoid unnecessary delay in model computation. One year is equivalent to a time step; this is equivalent to one calendar cropping season in the study area where most of the crops cultivated are annual crops.

Process overview and scheduling: One simulation consists of 12 main steps (Figure A1). Each major time loop of the simulation program is referred to as an annual production cycle. Each cycle integrates agent-based and patch-based processes.

\section{A2. Design Concepts (D)}

The Vea-LUDAS model is designed to take into account variation of human behavior with respect to agricultural land-use change decision-making. The design of the model also considered the possible implications of policy scenarios on household agricultural land-use change decision and household lielihood.

Emergence: Land-use change is caused by household agents, as well as human agents' willingness to adopt maize cultivation credit. Annual change experienced in the total area cultivated is associated with increasing household number in the study area [18]. Crop yield is a result of household inputs' (e.g., seed, labor, and fertilizer) interaction with landscape features (e.g., upslope, wetness index). Farm income is estimated from crop yield generated by each household.

Adaptation/learning: A household agent chooses the best agricultural land-use with respect to preference coefficient. The behavior of the closest agent group is adopted by the household agent [62,63]. Furthermore, household status is updated at the end of every time step and this influences their preference coefficient, hence their subsequent decision.

Prediction: A household agent is able to optimize spatial land-use choices only within his parcels.

Sensing: In evaluating land-use alternatives, it is assumed that household agents have absolute knowledge of the uniqueness of each landscape agent within their neighborhood spaces.

Interaction: Household agents interact directly when two or more households find their best land-use alternative in the same location. In this case, in a random manner one of them will have to leave that location and search for another plot [25]. Further, when a new household is created, information that will be useful for the new household agent is transferred from another household.

Stochasticity: Application of stochasticity in Vea-LUDAS occurs in four different processes, i.e., (i) choosing plot locations for household agents (initialization), as well as the new household created at each time step; (ii) preference coefficients in the land-use choice function; (iii) ecological sub-models 
that produce variability in the process; and (iv) some status variables not affected by agent-based processes (all defined by even distribution and pre-defined bounds).

Observation: This includes annually successive charts that describe temporal patterns of land-use/cover coverage, landholdings, yield and components, income and income components, and soil loss.

\section{A3. Details (D)}

Initialization: Vea-LUDAS followed initialization steps similar to those of VN-LUDAS [62]. Simulation and analysis were based on the sample households (186). The data on the sampled household are imported first, followed by the spatial data (land cover, elevation, upslope contributing area, wetness index, soil texture components, plot distance to river, and plot distance to irrigation area). This is followed by the land holding generation of the household agents, and each patch is assigned to a household.

\section{References}

1. Darwin, R. A farmer's view of the Ricardian approach to measuring agricultural effects of climatic change. Clim. Change 1999, 41, 371-411.

2. Fischer, G.; Shah, M.; van Velthuizen, H. Climate change and agricultural vulnerability. A Special Report Prepared by the International Institute for Applied Systems Analysis (IIASA) under United Nations Institutional Contract Agreement No. 1113 on "Climate Change and Agricultural Vulnerability”. In Proceedings of World Summit on Sustainable Development, Johannesburg, South Africa, 26 August-4 September 2002.

3. Vincent, K.; Joubert, A.; Cull, T.; Magrath, J.; Johnston, P. Overcoming the barriers: How to ensure future food production under climate change in Southern Africa. Oxfam Policy Pract.: Agric. Food Land 2011, 11, 183-242.

4. Gyasi, E.A.; Karikari, O.; Kranjac-Berisavljevic, G.; Vordzogbe, V.V. Study of Climate Change Vulnerability and Adaptation Assessment Relative to Land Management in Ghana; University of Ghana, Legon: Accra, Ghana, 2006.

5. Laube, W.; Awo, M.; Schraven, B. Erratic Rains and Erratic Markets: Environmental Change, Economic Globalisation and the Expansion of Shallow Groundwater Irrigation in West Africa (No. 30); ZEF Working Paper Series; University of Bonn: Bonn, Germany, 2008.

6. Stanturf, J.A.; Warren, M.L.; Charnley, S., Jr.; Polasky, S.C.; Goodrick, S.L.; Armah, F.; Nyako, Y.A. Ghana Climate Change Vulnerability and Adaptation Assessment; United States Agency for International Development: Washington, DC, USA, 2011.

7. Ramos, M.C.; Martínez-Casasnovas, J.A. Erosion rates and nutrient losses affected by composted cattle manure application in vineyard soils of NE Spain. Catena 2006, 68, 177-185.

8. Gitas, I.Z.; Douros, K.; Minakou, C.; Silleos, G.N.; Karydas, C.G. Multi-temporal soil erosion risk assessment in N. Chalkidiki using a modified usle raster model. EARSeL eProc. 2009, 8, 40-52.

9. Reusing, M.; Schneider, T.; Ammer, U. Modelling soil loss rates in the Ethiopian Highlands by integration of high resolution MOMS-02/D2-stereo-data in a GIS. Int. J. Remote Sens. 2000, 21, $1885-1896$. 
10. Stocking, M. Erosion and crop yield. In Encyclopedia of Soil Science; Dekker: New York, NY, USA, 2003; pp. 1-4.

11. Nyakatawa, E.Z.; Reddy, K.C.; Lemunyon, J.L. Predicting soil erosion in conservation tillage cotton production systems using the revised universal soil loss equation (RUSLE). Soil Tillage Res. 2001, 57, 213-224.

12. Sthiannopkao, S.; Takizawa, S.; Homewong, J.; Wirojanagud, W. Soil erosion and its impacts on water treatment in the northeastern provinces of Thailand. Environ. Int. 2007, 33, 706-711.

13. Ontl, T.A.; Schulte, L.A. Soil carbon storage. Nat. Educ. Knowl. 2012, 3, 35.

14. Eswaran, H.; Lal, R.; Reich, P.F. Land degradation: An overview. In Responses to Land Degradation, Proceedings of the 2nd International Conference on Land Degradation and Desertification, Khon Kaen, Thailand, 25-29 January 1999.

15. Jebari, S.; Berndtsson, R.; Olsson, J.; Bahri, A. Soil erosion estimation based on rainfall disaggregation. J. Hydrol. 2012, 436, 102-110.

16. EPA. National Action Programme to Combat Drought and Desertification; Environmental Protection Agency: Accra, Ghana, 2003.

17. Evans, R. Mechanics of water erosion and their Spatial and Temporal controls: An Empirical view point. In Soil Erosion; Kirkby, M.J., Morgan, R.P.C., Eds.; John Wiley and Sons: Chichester, UK, 1980; pp. 88-91.

18. Ghana Statistical Services. Population and Housing Census-Summary Report of Final Results; GSS: Accra, Ghana, 2012.

19. Adu, S.V. Eroded savanna soils of the Navrongo-Bawku area, northern Ghana. Ghana J. Agric. Sci. 1972, 5, 3-12.

20. Ghana Statistical Services. Ghana Living Standard Survey: Report of the Fourth Round (Ghana Living Standards Statistic 4); Ghana Statistical Services: Accra, Ghana, 2000.

21. IFAD. Ghana: Upper East Region Land Conservation and Smallholder Rehabilitation Project (LACOSREP) Report 2007; IFAD: Rome, Italy, 2007.

22. Mdemu, M.V. Water Productivity in Medium and Small Reservoirs in the Upper East Region (UER) of Ghana; Ecology and Development Series No. 59; University of Bonn: Bonn, Germany, 2008.

23. Van der Geest, K.; Dietz, T. A literature survey about risk and vulnerability in drylands with a focus on the Sahel. In The Impact of Climate Change on Drylands, with a Focus on West Africa; Dietz, A.J., Ruben, R., Verhagen, A., Eds.; Kluwer Academic Publishers: Dordrecht, The Netherlands; Boston, MA, USA; London, UK, 2004; pp. 117-146.

24. Badmos, B.K.; Villamor, G.B.; Agodzo, S.K.; Odai, S.N.; Guug, S.S. Examining agricultural land-use/cover change options in Rural Northern Ghana: A participatory scenario exploration exercise approach. Int. J. Interdiscip. Environ. Stud. 2014, 8, 15-35.

25. Le, Q.B.; Park, S.J.; Vlek, P.L.; Cremers, A.B. Land-Use Dynamic Simulator (LUDAS): A multi-agent system model for simulating spatio-temporal dynamics of coupled human-landscape system. I. Structure and theoretical specification. Ecol. Inform. 2008, 3, 135-153.

26. Schindler, J. A Multi-Agent System for Simulating Land-Use and Land-Cover Change in the Atankwidi Catchment of Upper East Ghana; Ecology and Development Series No. 68; Center for Development Research (ZEF): Bonn, Germany, 2009. 
27. Kaplan, M. Agent-Based Modelling of Land-Use Changes and Vulnerability Assessment in a Coupled Socio-Ecological System in the Coastal Zone of Sri Lanka; Ecology and Development Series No. 77, 2011; Center for Development Research (ZEF): Bonn, Germany, 2011.

28. Villamor, G.B.; le, Q.B.; Djanibekov, U.; van Noordwijk, M.; Vlek, P.L. Biodiversity in rubber agroforests, carbon emissions, and rural livelihoods: An agent-based model of land-use dynamics in lowland Sumatra. Environ. Model. Softw. 2014, 61, 151-165.

29. Grimm, V.; Berger, U.; Bastiansen, F.; Eliassen, S.; Ginot, V.; Giske, J.; DeAngelis, D.L. A standard protocol for describing individual-based and agent-based models. Ecol. Model. 2006, $198,115-126$.

30. Grimm, V.; Berger, U.; DeAngelis, D.L.; Polhill, J.G.; Giske, J.; Railsback, S.F. The ODD protocol: A review and first update. Ecol. Model. 2010, 221, 2760-2768.

31. Wilensky, U. NetLogo 1999. Available online: http://ccl.northwestern.edu/netlogo/ (accessed on 24 June 2015).

32. Wischmeier, W.H.; Smith, D.D. Predicting Rainfall Erosion Losses-A Guide to Conservation Planning. Predicting Rainfall Erosion Losses-A Guide to Conservation Planning; Agriculture Handbook No. 537; USDA/Science and Education Administration, US. Govt. Printing Office: Washington, DC, USA, 1978.

33. Roose, E.J. Use of the universal soil loss equation to predict erosion in West Africa. In Soil Erosion: Prediction and Control, Proceedings of the National Conference on Soil Erosion; Soil Conservation Society of America: Ankeny, IA, USA, 1977; pp. 143-151.

34. Fournier, F. Climate and Erosion; University Press Paris: Paris, France, 1960.

35. Roose, E.J. Use of the universal soil loss equation to predict erosion in west Africa. In Soil Erosion. Prediction and Control SCSA, Special Publication; Soil Conservation Society of America: Ankeny, IA, USA, 1976, Volume 21, pp. 60-74.

36. Arnoldus, H.M.J. Methodology Used to Determine the Maximum Potential Average Annual Soil Loss Due to Sheet and Rill Erosion in Morocco; FAO Soils Bulletins; FAO: Rome, Italy, 1977.

37. Kassam, A.H. Agro-Ecological Land Resources Assessment for Agricultural Development Planning: A Case Study of Kenya: Resources Data Base and Land Productivity; Food Agriculture Organisation: Rome, Italy, 1991.

38. Singh, G.; Babu, R.; Narain, P.; Bhushan, L.S.; Abrol, I.P. Soil erosion rates in India. J. Soil Water Conserv. 1992, 47, 97-99.

39. Williams, J.R.; Jones, C.A.; Dyke, P. Modeling approach to determining the relationship between erosion and soil productivity. Trans. Am. Soc. Agric. Eng. 1984, 27, 129-144.

40. Shirazi, M.A.; Boersma, L. A unifying quantitative analysis of soil texture. Soil Sci. Soc. Am. J. 1984, 48, 142-147.

41. Zhang, K.L.; Shu, A.P.; Xu, X.L.; Yang, Q.K.; Yu, B. Soil erodibility and its estimation for agricultural soils in China. J. Arid Environ. 2008, 72, 1002-1011.

42. Wischmeier, W.H.; Johnson, C.B.; Cross, B.V. Soil erodibility nomograph for farmland and construction sites. J. Soil Water Conserv. 1971, 26, 189-193.

43. Geleta, H.I. Watershed Sediment Yield Modeling for Data Scarce Areas. Ph.D. Thesis, University of Stuttgart, Stuttgart, Germany, 2011. 
44. FAO/Unesco/ISRIC. Revised Legend of the Soil Map of the World; World Soil Resources Report; FAO: Rome, Italy, 1990.

45. Borah, D.K.; Krug, E.C.; Yoder, D. Watershed sediment yield. Sediment. Eng.: Process. Meas. Model. Pract. ASCE Man. Rep. Eng. Pract. 2008, 110, 827-858.

46. Moore, I.D.; Burch, G.J. Physical basis of the length-slope factor in the Universal Soil Loss Equation. Soil Sci. Soc. Am. J. 1986, 50, 1294-1298.

47. Morgan, R.P.C.; Davidson, D.A. Soil Erosion and Conservation; Longman Group: Harlow, UK, 1991.

48. Moore, I.D.; Turner, A.K.; Wilson, J.P.; Jenson, S.K.; Band, L.E. GIS and land-surface-subsurface process modeling. In Environmental Modeling with GIS; Goodchild, M.F.R., Parks, B.O., Steyaert, L.T., Eds.; Oxford University Press, Inc.: Oxford, UK, 1993; pp. 196-230.

49. Van der Knijff, J.; Jones, R.J.A.; Montanarella, L. Soil Erosion Risk Assessment in Italy; European Soil Bureau, European Commission: Brussels, Belgium, 1999; p. 52.

50. Zhang, Y.; Liu, B.; Zhang, Q.; Xie, Y. Effect of different vegetation types on soil erosion by water. Acta Bot. Sin. 2002, 45, 1204-1209.

51. Hazarika, M.K.; Honda, K. Estimation of soil erosion using remote sensing and GIS: Its valuation and economic implications on agricultural production. In Sustaining the Global Farm; Scott, D.E., Mohtar, R.H., Steinhardt, G.C., Eds.; USDA-ARS national soil erosion research laboratory: Purdue, IN, USA, 2001; pp. 1090-1093.

52. Karaburun, A. Estimation of $\mathrm{C}$ factor for soil erosion modeling using NDVI in Buyukcekmece watershed. Ozean J. Appl. Sci. 2010, 3, 77-85.

53. Henao, J.; Baanante, C.A. Estimating Rates of Nutrient Depletion in Soils of Agricultural Lands of Africa; International Fertilizer Development Center: Muscle Shoals, AL, USA, 1999; p. 76.

54. Villamor, G.B.; Badmos, B.K. Grazing game: A learning tool for adaptive management in response to climate variability in semi-arid areas of Ghana. Ecol. Soc. 2015, under review.

55. Angelucci, F. Analysis of Incentives and Disincentives for Maize in Ghana; Technical Notes Series; MAFAP, FAO: Rome, Italy, 2012.

56. Villamor, G.B. Flexibility of Multi-agent System Models for Rubber Agroforest Landscapes and Social Response to Emerging Reward Mechanisms for Ecosystem Services in Sumatra, Indonesia; Ecology and Development Series No. 88, 2012; Center for Development Research (ZEF): Bonn, Germany, 2012.

57. Villamor, G.B.; Troitzsch, K.G.; van Noordwijk, M. Validating human decision making in an agent-based land-use model. In Proceedings of the 20th International Congress on Modelling and Simulation (MODSIM): Adapting to Change: The Multiple Roles of Modelling, Adelaide, Australia, 1-6 December 2013.

58. Niazi, M.; Hussain, A. Agent-based computing from multi-agent systems to agent-based models: A visual survey. Scientometrics 2011, 89, 479-499.

59. Villamor, G.B.; van Noordwijk, M; Troitzsch, K.G.; Vlek, P.L.G. Human decision making in empirical agent-based models: Pitfalls and caveats for land-use/change policies. In Proceedings of the 26th European Conference on Modelling and Simulation, Koblenz, 29 May-1 June 2012. 
60. Villamor, G.B.; van Noordwijk, M.; Troitzsch, K.G.; Vlek, P.L.G. Human decision making for empirical agent-based models: construction and validation. In Proceedings of the 6th Biennial Meeting, International Environmental Modelling and Software, Managing Resources of a Limited Planet, Leipzig, Germany, 1-5 July 2012.

61. McSweeney, C.; Lizcano, G.; New, M.; Lu, X. The UNDP Climate change country profiles: Improving the accessibility of observed and projected climate information for studies of climate change in developing countries. Bull. Am. Meteorol. Soc. 2010, 91, 157-166.

62. Le, Q.B.; Park, S.J.; Vlek, P.L. Land Use Dynamic Simulator (LUDAS): A multi-agent system model for simulating spatio-temporal dynamics of coupled human-landscape system: 2. Scenario-based application for impact assessment of land-use policies. Ecol. Inform. 2010, 5, 203-221.

63. Le, Q.B.; Seidl, R.; Scholz, R.W. Feedback loops and types of adaptation in the modelling of land-use decisions in an agent-based simulation. Environ. Model. Softw. 2012, 27, 83-96.

(C) 2015 by the authors; licensee MDPI, Basel, Switzerland. This article is an open access article distributed under the terms and conditions of the Creative Commons Attribution license (http://creativecommons.org/licenses/by/4.0/). 